\title{
Baker Leads MRS Board of Directors for 2009
}

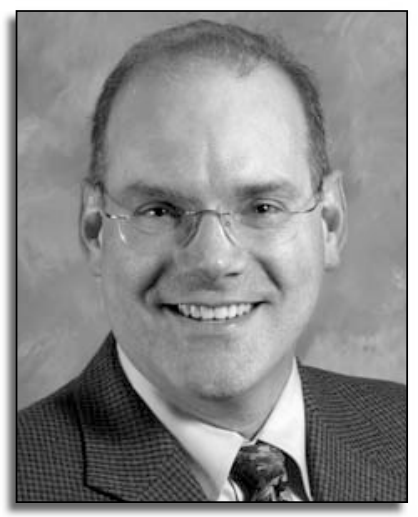

Shefford P. Baker President

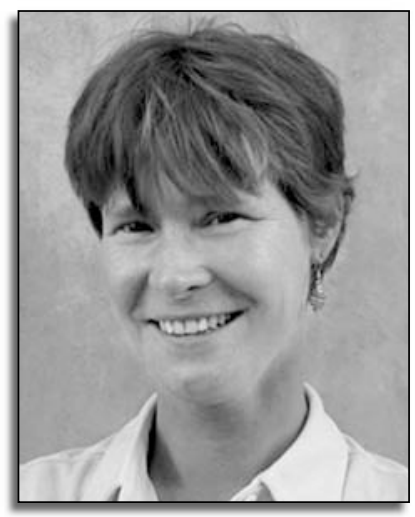

Cynthia A. Volkert Immediate Past President

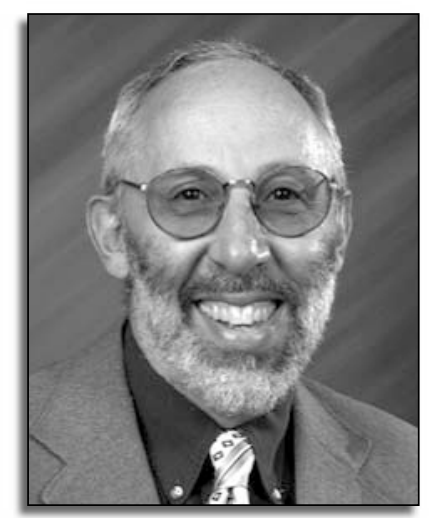

David S. Ginley

Vice President/President-Elect

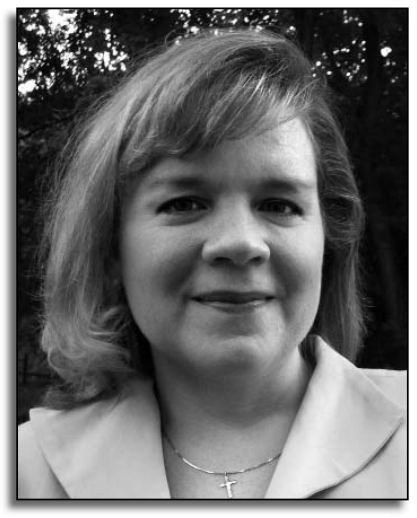

Bethanie J.H. Stadler Secretary

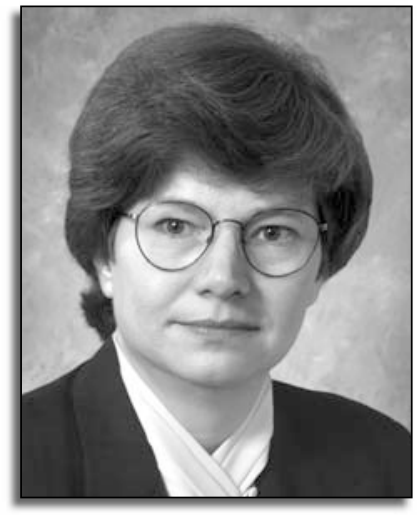

Linda L. Horton Treasurer
On January 1, Shefford P. Baker (Cornell University) assumed the presidency of the Materials Research Society for 2009, after serving as vice president/ president-elect for 2008. He succeeded Cynthia A. Volkert (University of Göttingen), who now serves MRS as immediate past president.

In last fall's annual election of officers and directors, David S. Ginley (National Renewable Energy Laboratory) was elected vice president/president-elect. Bethanie J.H. Stadler (University of Minnesota) continues serving her term as MRS secretary, and Linda L. Horton (Oak Ridge National Laboratory) was appointed by the Board of Directors to serve as MRS treasurer.

The newly elected members to the MRS board of directors are Eberhard Bodenschatz, Max Planck Institute for Dynamics and Self Organization; Jim De Yoreo, Lawrence Berkeley National Laboratory; Christine A. Orme, Lawrence Livermore National Laboratory; Michael F. Rubner, Massachusetts Institute of Technology; and Takao Someya, the University of Tokyo. They join continuing
Board of Directors J. Charles Barbour, Sandia National Laboratories; Ian W. Boyd, University College London; Yves J. Chabal, University of Texas at Dallas; Susan P. Ermer, Lockheed Martin Advanced Technology Center; Mary E. Galvin, Air Products and Chemicals, Inc.; Charles C. Han, Chinese Academy of Sciences; Gregg S. Higashi, ALTA Devices; Cherie Kagan, University of Pennsylvania; James C. Sturm, Princeton University; Richard A. Vaia, U.S. Air Force Research Laboratory; and Timothy P. Weihs, the John Hopkins University.

\section{Shefford P. Baker \\ President}

Shefford P. Baker is associate professor in Materials Science and Engineering at Cornell University. After completing an undergraduate degree in music and a brief career as a professional musician and music teacher, he went back to school, receiving his $\mathrm{PhD}$ degree in materials science and engineering at Stanford University in 1993 . He was a staff scientist at the Max Planck Institute for Materials Research in Stuttgart from 1993 to 1997 and joined the Cornell faculty in 1998.

Baker's research focuses on the unique mechanical properties of materials having microstructural or dimensional length scales in the nanometer regime. Recent achievements include discovery of a new microstructure in Ta thin films and characterization of the phase transformation that produces it, $x$-ray studies of stress states and relaxation in different texture components in thin metal films, dislocation dynamics simulations and analytical modeling of dislocation structures in thin layers, quantitative measurements of bonding at interfaces by time-dependent delamination experiments, and quantification of the structure-property relationships in the lamellar and interlamellar regions in trabecular bone as a function of age and vitamin D deficiency.

For MRS, Baker has organized five symposia and taught numerous tutorials, was a 2004 MRS Fall Meeting (F04) Chair, served on the Public Outreach Committee, and was elected to the board of directors in 2005, where he served as chair of the External Relations Committee. He generated a project to bring 100 high school teach- 
ers to the F04 meeting and worked with principal investigators from several major science museums to create the Nanoscale Informal Science Education (NISE) Network and to promote and define the MRS role in it. Baker served as MRS Vice President/President-Elect in 2008.

\section{David S. Ginley}

Vice President/President-Elect

David S. Ginley is a research fellow and group manager of the Process Technology and Advanced Concepts group at the National Renewable Energy Laboratory in Golden, Colorado. His work focuses on the basic science and development of new technology related to the conversion and storage of solar energy. Key areas of focus are organic-based solar cells, atmospheric processing and direct-write materials, combinatorial materials development, and the incorporation of nanotechnology in energy-related generation, storage, and conversion technologies. Materials activities are specific to developing new materials and hybrid composite materials, including transparent conducting oxides, ferroelectric materials, and hybrid structures at the nanoscale of organic/organic or organic/inorganic systems. Ginley received a $\mathrm{PhD}$ degree in inorganic chemistry from the Massachusetts Institute of Technology. He has published more than 320 papers, received 28 patents, and been honored with a Department of Energy Award for Sustained Research in Superconducting Materials, five R\&D 100 awards, and three Federal Laboratory Consortium technology transfer awards. $\mathrm{He}$ is an adjunct professor of physics at Colorado University-Boulder, and a research professor of materials science at the Colorado School of Mines.

For MRS, Ginley has served as secretary, treasurer, and chair of the Board of Directors' Operational Oversight Committee. He was a Meeting Chair for the 2005 MRS Fall Meeting and has organized numerous symposia. He is a Principle Editor for the Journal of Materials Research. He also served on the MRS Bulletin Energy Project Organizing Committee for the magazine's special issue on "Harnessing Materials for Energy" (April 2008).

\section{Bethanie J.H. Stadler}

Secretary

Bethanie J.H. Stadler is an associate professor at the University of Minnesota. Stadler received her $\mathrm{PhD}$ degree from the Massachusetts Institute of Technology (1994) in materials science and engineering. Prior to joining the University of Minnesota, she was a National Research Council postdoctoral fellow working in the Optoelectronics Division of the Air Force Rome Laboratory. This spring, she will be working at IMEC in Leuven Belgium. Stadler's honors and awards include various teaching awards, the NSF CAREER award, and the University of Minnesota McKnight Presidential Fellowship. Stadler is currently working on magnetic nanowires for magnetoelectronics and sensors, and semiconductor-intergrated magnetooptical garnets for photonics.

For MRS, Stadler served the Board of Directors on all three governing subcommittees, including co-chair of the Operations and chair of the Planning committee. She has also served as chair of the Academic Affairs committee, co-organized three symposia in the areas of photonics and magnetics, and co-chaired the 2004 MRS Fall Meeting.

\section{Linda L. Horton \\ Treasurer}

Linda L. Horton is director of the Oak Ridge National Laboratory (ORNL) nanoscale research facility, the Center for Nanophase Materials Sciences (CNMS). She also has programmatic responsibility for the Shared Research Equipment User Program. Her personal research emphasized applications of electron microscopy to materials science problems including investigations of the effects of ion implantation and neutron irradiation on the structure and properties of ferritic alloys and ceramic materials and studies of the growth and characterization of diamond thin films. She has been at ORNL since 1981 and had held a number of program and line management roles since 1990. Horton holds a PhD and an MS degree in materials science from the University of Virginia. Her honors include award recognition from the Department of Energy and from ASM International (including Fellow). She serves on a number of academic and advisory committees in the United States and abroad.

For MRS, Horton revised the Constitution for the Society and was engaged in implementing the reorganization of the Society's governance. She served as the chair of the Operational Oversight Committee for two years and was the MRS Treasurer in 2003. She also served on several task forces for assessments of meeting programs and publications, and she has served on one of the awards subcommittees.

\section{Cynthia A. Volkert}

Immediate Past President

Cynthia A. Volkert is a professor at the Institute of Materials Physics at the University of Göttingen, where she has been since October 2007. She studied physics at McGill University (Bachelor's degree) and Harvard University (PhD degree) and then spent 10 years as a staff member at Bell Laboratories in New Jersey. In 1999, she moved to Germany where she worked first at the Max Planck Institute for Metals Research in Stuttgart and then at the Forschungszentrum Karlsruhe, prior to moving to Göttingen.

Volkert's research is focused on stability and mechanical behavior of nanostructured materials. She has worked on structural relaxation and flow in metallic glasses, effects of ion irradiation on solids, strain relaxation in heteroepitaxial films, stress effects on optical properties of glasses, phase changes on very short time scales, mechanical properties of thin metal films, and electromigration in thin films. Most recently, she has used various micromechanical methods to perform ex situ and in situ investigations of deformation and dislocation dynamics in small dimensions.

In addition to her involvement in several committees, Volkert has served as MRS president, vice president/president-elect, secretary, treasurer, chair of the Operational Oversight Committee for the board of directors, and she has been an organizer for a number of symposia and a meeting chair for the 2001 MRS Spring Meeting.

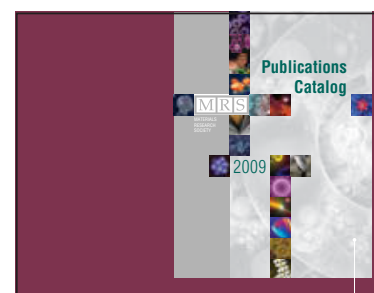

MRS Publications Catalog

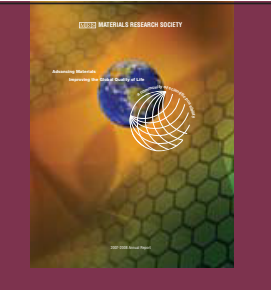

MRS Annual Report

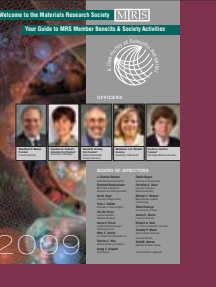

MRS Member Guide
New 2009 MRS Publications

Contact MRS today for your copy

info@mrs.org 


\section{Anseth, Chen, Gumbsch, and Zhao to Chair 2009 MRS Fall Meeting}

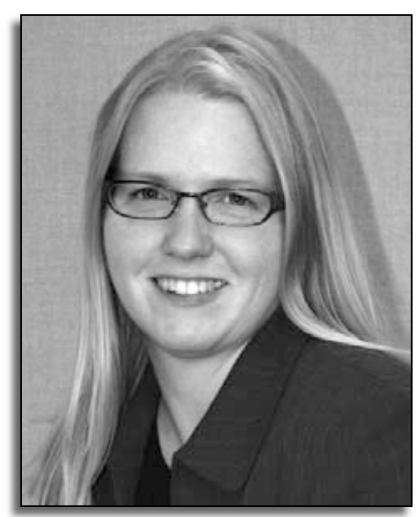

Kristi S. Anseth

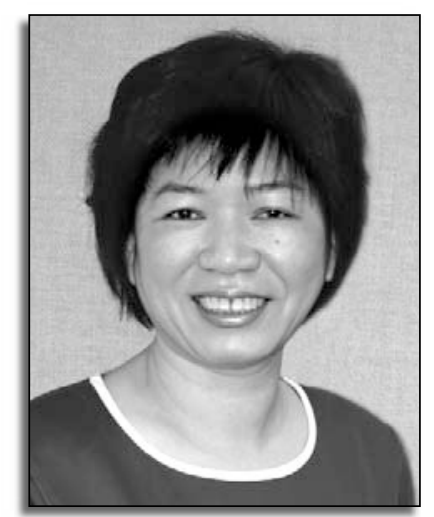

Li-Chyong Chen

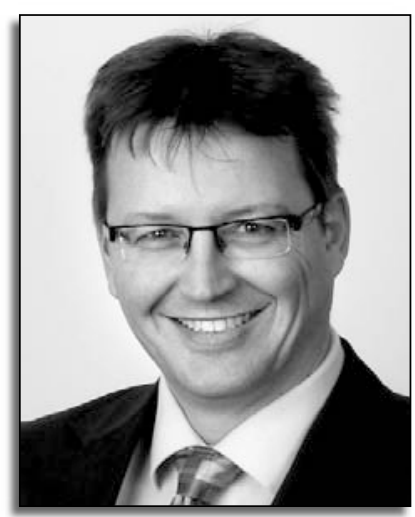

Peter Gumbsch

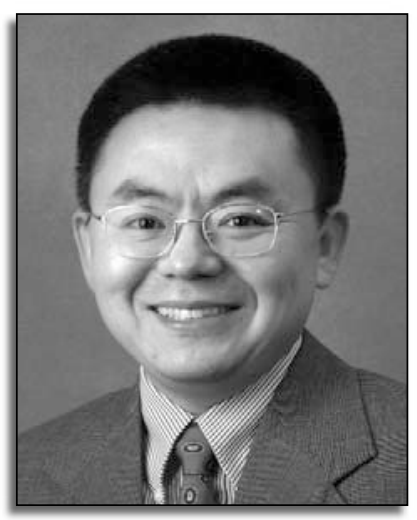

J.-C. Zhao
The 2009 Materials Research Society Fall Meeting in Boston, November 30December 4, will be chaired by Kristi S. Anseth (University of Colorado), Li-Chyong Chen (National Taiwan University), Peter Gumbsch (University of Karlsruhe and Fraunhofer-Institut für Werkstoffmechanik IWM), and Ji-Cheng Zhao (The Ohio State University). Updated information on the meeting is available at www.mrs.org.

Kristi S. Anseth is the Tisone Professor, Associate Professor of Surgery, and Howard Hughes Medical Institute Investigator at the University of Colorado at Boulder. Her research focuses on pursuing new directions toward the rational design of biomaterials and, specifically, how photopolymerization processes can be used to provide numerous advantages for medical applications. For the past few years, her research group has been exploring, designing, and characterizing new generations of multifunctional macromers that can be photopolymerized to form degradable networks, where the degradation is predictable and readily controlled. Other projects include the design of new orthopaedic biomaterials for fracture fixation, photoencapsulation of chondrocytes for cartilage tissue engineering, biomimetic approaches to heart valve tissue engineering, microfluidic bioassays, photopolymerization of microand nanoparticles for drug delivery, DNA delivery for tissue engineering applications, and photopolymerizable tissue adhesives. Anseth's awards and honors include, in 2008, Distinguished Professor of the University of Colorado, named by CU Board of Regents; the Distinguished Engineering Alumni Award, University of Colorado; and the Clemson Award for Basic Research from the Society for Biomaterials. She is a Fellow of the American Association for the Advancement of Science (2006) and the American Institute for Medical and Biological Engineering (2001), and she received the Materials Research Society Outstanding Young Investigator Award in 2001. Anseth serves on the editorial board of numerous journals, including Journal of Biomedical Materials ResearchPart A and Science. Anseth has over 160 publications.

Li-Chyong Chen is a Distinguished Research Fellow in the Center for Condensed Matter Sciences (CCMS) at National Taiwan University (NTU). She received her BS degree in physics from NTU (1981) and her PhD degree in applied physics from Harvard University (1989). In 2007, she was offered an honorary doctoral degree from Linkoping University, Sweden. After completing her graduate study, she joined the General Electric Corporate Research and Development (now GE Global Research), Niskayuna, NY (1989-1994), as a technical staff member. She returned to Taiwan in 1994 assuming a faculty position at NTU. Over the last decade, her expertise has been mainly in the field of carbon and nitride materials. Her group has established a strong program on onedimensional nanomaterials, including carbon nanotubes, group-III nitride nanowires and Si nanotips. She also specializes in integrated micro-devices for optical, electrical, energy, and sensing applications. Chen owns eight patents and has written six book chapters and published over 180 papers in internationally refereed journals, including Nature Materials and Nature Nanotechnology. Her work on nanopeapods published in Nature Materials (2006) has been selected as a Fast Breaking Paper and a few other papers have also been listed as highlycited articles by ISI. Chen has organized several professional meetings and served on the Editorial Advisory Board of a few journals, including Critical Reviews in Solid State and Materials Sciences, Taylor and Francis since 2004. She was also an Associate Editor of the Journal of Vacuum Science and Technology B-Microelectronics and Nanostructures (2004-2006).

Peter Gumbsch is chair for mechanics of materials at the University of Karlsruhe and head of the Fraunhofer Intitute for Mechanics of Materials in Freiburg and Halle. He studied economics at the University of Hagen and physics at the University of Stuttgart, where he also earned his Dr. rer. nat. degree in 1991. After research periods at Sandia National Laboratories in Livermore, Imperial College in London, and at Oxford University, he returned to the Max Planck Institute for Metals Research in Stuttgart, Germany. In 2001, he accepted the positions at Karlsruhe and Fraunhofer. Gumbsch's research activities focus on modeling and simulation of structural materials, in particular multiscale modeling approaches. His activities cover atomistic simulation and mesoscopic modeling as well as macroscopic materials descriptions. His central research topics are deformation and fracture processes as well as interface properties in metals and ceramics. Gumbsch is author of more than 100 refereed journal publications. Among his honors and awards are the Max Planck Medal (1992), the Masing Memorial Award (1998), and the Gottfried Wilhelm Leibniz Prize (2007).

J.-C. Zhao joined the Department of Materials Science and Engineering of The Ohio State University in January 2008 after a 12-year career as a materials scientist and project/team leader at GE Global Research in Niskayuna, NY. He joined GE after obtaining his $\mathrm{PhD}$ degree in materials science and engineering from Lehigh University in 1995. His research from 1995 
to 2002 focused on phase diagrams, thermodynamics, high-throughput methodologies, diffusion, and design of advanced alloys and coatings for jet engine applications. Since 2003, he has also been working on the development of hydrogen storage materials. In addition to many materials innovations, Zhao created a diffusionmultiple approach for accelerated materials discovery and co-developed several materials property microscopy tools. Zhao has received several honors includ- ing the Geisler Award from ASM International and the Hull Award from GE Global Research, and was elected a Fellow of ASM International in 2003. He has published about 70 articles and edited/co-edited three books. Zhao holds 38 U.S. patents with 27 more pending. He serves as an associate editor for the Journal of Phase Equilibria and Diffusion and on the editorial board of Advanced Engineering Materials. His innovations were featured in news, covers, and a cover story in
Nature, CEE News, MRS Bulletin, and Advanced Engineering Materials. His involvement with MRS includes guest editor of two theme issues of $M R S$ Bulletin, 2006 volume organizer of MRS Bulletin, and co-organizer of a symposium at the 2006 MRS Fall Meeting, as well as serving on the Book Review Board of MRS Bulletin and an MRS Industrial Meeting Participation Task Force.

\section{MRS Bulletin Volume Organizers Guide Technical Theme Topics for 2010}

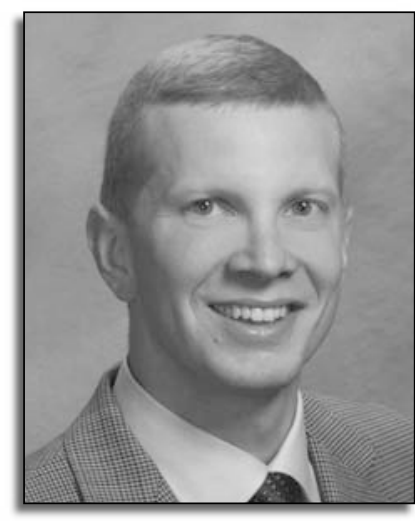

T. John Balk

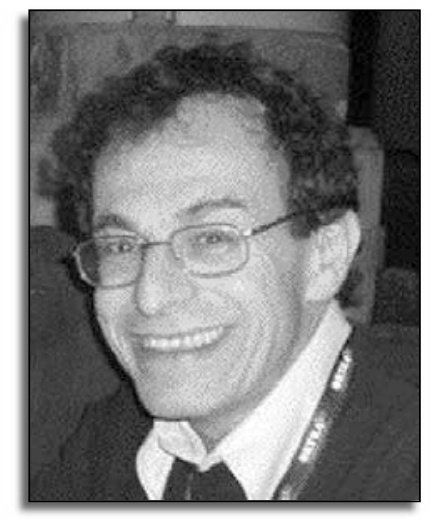

David Cahen

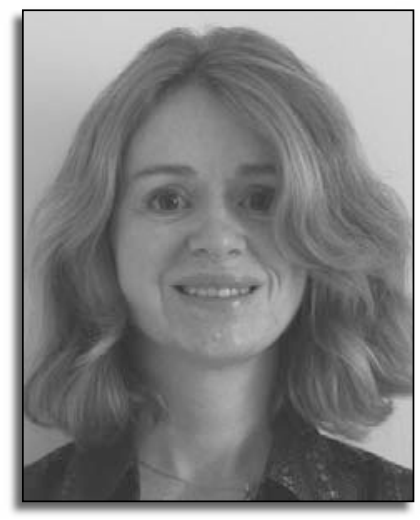

Fiona Meldrum

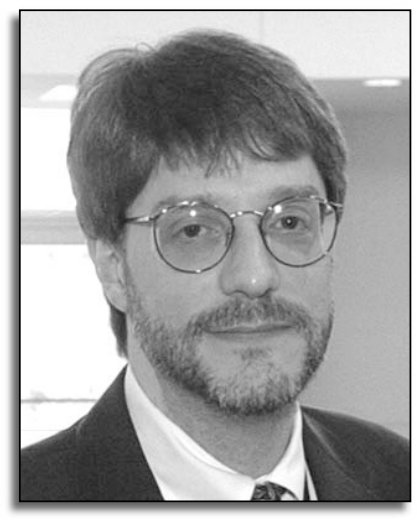

Stephen Streiffer
The MRS Bulletin 2010 volume organizers, who will guide the development of theme topics for the 2010 volume year, are John Balk (University of Kentucky, USA), David Cahen (Weizmann Institute of Science, Israel), Fiona Meldrum (University of Bristol, UK), and Stephen Streiffer (Argonne National Laboratory, USA). Requests for instructions on submitting proposals for MRS Bulletin theme topics can be e-mailed to bulletin@mrs.org.

John Balk is an assistant professor in the Department of Chemical and Materials Engineering at the University of Kentucky. $\mathrm{He}$ received his $\mathrm{BS}$ degree from the University of California, Berkeley, where he double-majored in mechanical engineering and materials science and engineering. He received his $\mathrm{PhD}$ and MS degrees in materials science and engineering from The Johns Hopkins University. Before joining the faculty at the University of Kentucky, he was a staff scientist at the Max Planck Institute for Metals Research in Stuttgart, Germany, where he also completed his postdoctoral work. His research focuses on structure-property relationships in the mechanical behavior of metals and alloys, primarily ones that allow the study of size effects. Currently he is working to under- stand the deformation mechanisms that operate in nanoporous noble metals. He has helped organize three symposia for the Materials Research Society and serves on the MRS Web Advisory and Content Capture Subcommittees. He is faculty advisor to the Material Advantage student chapter at Kentucky and is chair of the ASM Bluegrass Chapter. In 2007, he was awarded the Bradley Stoughton Award for Young Teachers from ASM International, and in 2008 he received an NSF CAREER Award. He was elected vice-chair of the 2010 (and chair of the 2012) Gordon Research Conference on Thin Film and Small-Scale Mechanical Behavior.

David Cahen is head of the Department of Materials and Interfaces at Weizmann Institute of Science, Israel. Since 2007, he also heads the Schmidt Minerva Center on Supramolecular Architecture and the Mary and Tom Beck Canadian Center for Alternative Energy Research. He is the scientific director of Weizmann's Alternative Sustainable Energy Research Initiative, chair of the users committee of the Nanosciences Lab and the incumbent of the Rowland and Sylvia Schaefer Professorial Chair in Energy Research. He received his BSc degree in chemistry and physics from the Hebrew University of Jerusalem (1969) and his PhD degree in chemistry and materials research from Northwestern University (1973). He pursued postdoctoral research in the biophysics of photosynthesis at the Hebrew University of Jerusalem and at the Weizmann Institute. In 1976, he joined the Weizmann Institute, where he was tenured in 1982 . He was promoted to associate and full professor in 1993 and 1998, respectively. Cahen's main research interests lie in exploring chemical means to control the electronic and optical properties of materials, with a current focus on understanding how molecules can control the transport of electrons in optoelectronic materials and devices, including solar cells and sensors. Cahen's awards and honors include the Edwards Prize for Research Excellence (Israel Vacuum Society, 2003) and the 2008 Landau Prize for Chemistry. He has served and serves on various national and international committees concerned with science and science education, as well as consultant or scientific advisory board member of several energyrelated companies and initiatives.

Fiona Meldrum is a Reader at the School of Chemistry, University of 
Bristol, UK. She obtained her undergraduate degree in Natural Sciences from the University of Cambridge in 1989, and her doctorate in biological crystallization from the University of Bath in 1992. Following a postdoctoral position at the University of Syracuse, she carried out further postdoctoral work at the Max Plank Institute of Polymerforschung, Mainz, under award of a Humbold Research Fellowship. Meldrum then joined the Australian National University in Canberra, before returning to the United Kingdom to take up a lectureship at Queen Mary, University of London. In 2003, Meldrum moved to the School of Chemistry, University of Bristol. Her current research focuses on crystallization, with particular emphasis on biomineralization and bio-inspired crystal growth, where natural systems are used as an inspiration for the design and synthesis of crystalline and amorphous minerals. Meldrum has authored many papers in the field and has co-organized symposia on related topics at conferences including
Materials Research Society and American Chemical Society meetings.

Stephen Streiffer is the (acting) director of Argonne National Laboratory's Center for Nanoscale Materials, a Department of Energy national user facility that provides capabilities explicitly tailored to the creation and characterization of new functional materials on the nanoscale. He holds a $\mathrm{PhD}$ degree in materials science and engineering from Stanford University (1993) and a bachelor's degree in materials science and engineering from Rice University (1987). Streiffer's scientific expertise is in nanostructured complex oxides and in structural characterization of materials, particularly using transmission electron microscopy and $x$-ray scattering techniques. His active research projects focus on utilizing in situ synchrotron $x$-ray methods to probe chemical vapor deposition of complex oxides as well as phase transformations and nanoscale size effects in ferroic thin films. He is also currently involved in in situ synchrotron x-ray studies of the synthesis of InGaN heterostructures, as part of an effort to expand the basic understanding of materials for energy-efficient solid-state lighting. Streiffer is an active member of the Materials Research Society and Institute of Electrical and Electronics Engineers, and a Fellow of the American Physical Society. $\mathrm{He}$ also serves on the Ferroelectrics Committee of the IEEE Ultrasonics, Ferroelectrics, and Frequency Control Society and is a member of the Ferroelectrics Standard Committee of the IEEE. He has been a tutorial instructor for MRS and the IEEE Microwave Theory and Techniques Society. Streiffer was awarded The IEEE UFFC Ferroelectrics Young Investigator Award in 2006; a sabbatical fellowship by the École Polytechnique Fédérale de Lausanne, Switzerland in 2005; received an Alexander von Humboldt-Stiftung Postdoctoral Fellowship in 1993; and was awarded an Electron Microscopy Society of America Presidential Award in 1991. He has authored or co-authored more than 150 scientific publications, and holds one patent.

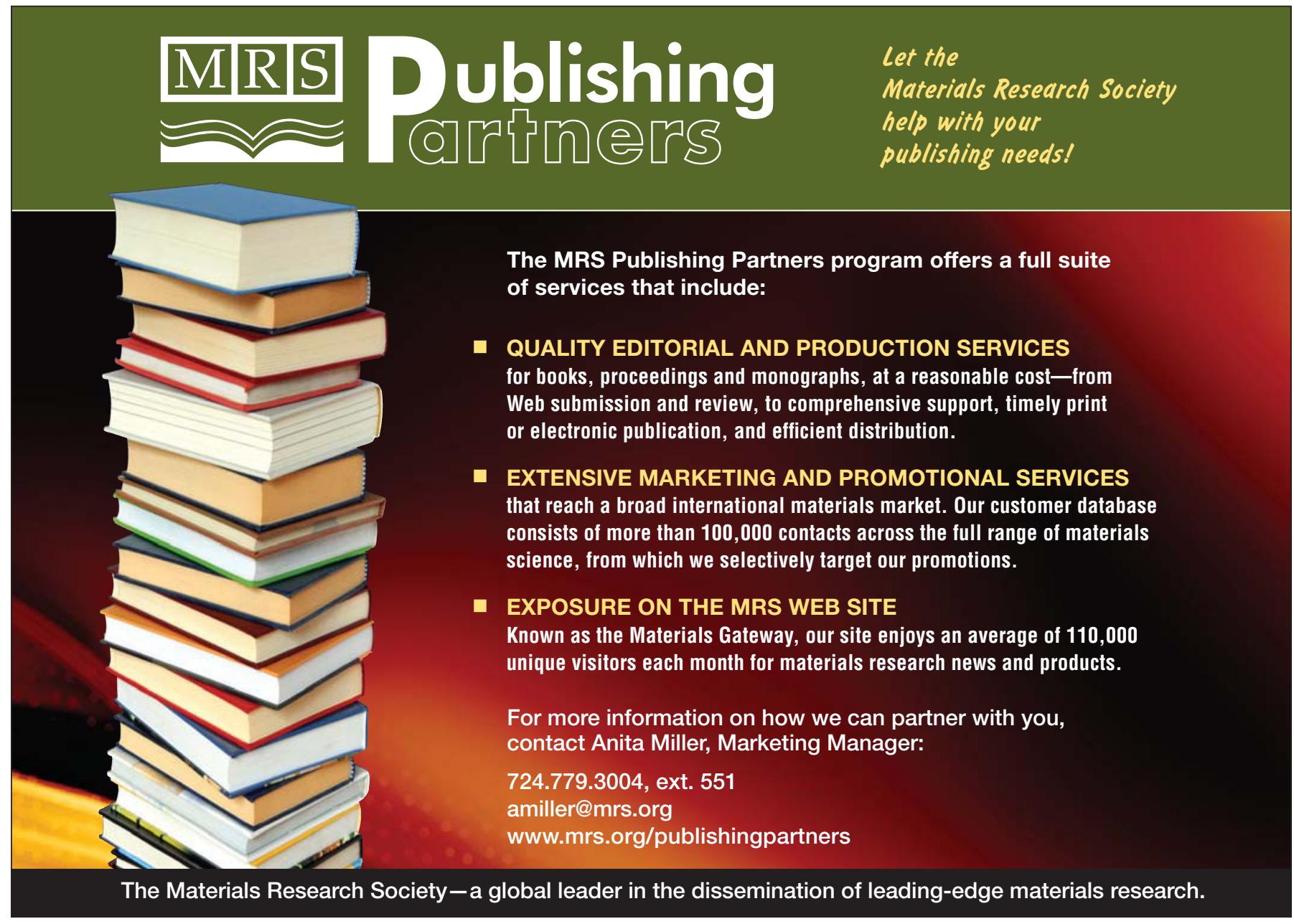

